\title{
On the problem of the pathology of spasmodic torticollis in man
}

\author{
EDWARD TARLOV 1 \\ From the National Hospital for Nervous Diseases, Queen Square, London
}

SUMMARY Those regions which have been implicated by experimental and clinical neuropathological studies in the pathogenesis of spasmodic torticollis were examined in detail in the present patient and no histological abnormalities found. In the light of marked species differences in the effects of certain brain lesions on posture and the findings reported here, the pathogenesis of spasmodic torticollis in man may well be different from its pathogenesis in experimental animals.

Although the striking clinical features of human spasmodic torticollis are well known to neurologists (see Wilson, 1955) the pathological basis of this disorder has never convincingly been demonstrated. Previous studies of human pathological cases (Foerster, 1933; Grinker and Walker, 1933; Alpers and Drayer, 1937) leave considerable doubt as to the significance of the lesions described. Although experimental studies (see below) have indicated a number of focal brain-stem lesions which produced abnormal neck postures in experimental animals, the species differences in the effects of certain brainstem lesions on neck posture in primates (Tarlov, 1969) make it seem somewhat doubtful whether human spasmodic torticollis results from lesions similar to those which produce the disorder in laboratory animals.

There is among the published reports of the neuropathology of human spasmodic torticollis no mention of a study of those regions in which lesions in experimental animals produce spasmodic torti- collis. Fortunately, Dr. Marion C. Smith had in her collection the brain of a patient with spasmodic torticollis who had been carefully investizated during life. Dr. Smith's routine examination had revealed nothing abnormal, but in the light of the experimental findings it was of considerable interest to make a detailed examination of the brain in such a case.

\footnotetext{
1Present address: Neurosurgical service, Massachusetts General Hospital, Boston, Massachusetts, U.S.A.
}

\section{CASE REPORT}

(NHQS 82509) A woman, 65 years old at death, had had a six year history of spasmodic torticollis, consisting of spasms of anterior and left lateral flexion of the neck associated with a static abnormality of neck posture. Involuntary movements were much exaggerated when she was up and about. Death was due to bronchopneumonia.

HISTORY She was admitted to the National Hospital, Queen Square, on 14 November 1958 under the care of Dr. Eliot Slater. Two years before, when aged 61 , the patient began to have aching and stiffness at the back of her neck while at work in a factory assembly line. Her neck began flexing laterally to the left in the summer of 1957. This gradually progressed over the next six months until by January 1958 her left ear was approximated to her left shoulder. When she tried to bring her head to a normal position, involuntary spasmodic torsion movements returned it to its abnormal position. When lying down she was able to bring her head to a more normal position. Her spasmodic movements gradually decreased over the next few years. They were not apparent at rest but would appear, to a lesser extent than before, when she attempted to bring her head to an erect position. Her tonic abnormal neck posture was maintained.

When 39 years old she had sustained severe electrical burns to her left hand during a bombing raid and for the following three months she was unable to speak above a whisper. Otherwise there was no difficulty with speech or swallowing, nor any other involuntary movements. There had been no serious head or neck injuries at any time, nor any history of otological disorders. There was no history of encephalitis or any significant family history. 
She lived alone, her alcoholic husband having left her in 1933; she had been glad to see him go and subsequently led a calm and quiet life. She had four children. She had worked at the same job for 17 years before the onset of her torticollis. She stopped working two years after its onset, apparently because of the disability it occasioned.

Physical examination When examined (Dr. A. K. Ommaya) on 14 November 1958 she held her neck laterally flexed to the left, with her occiput deviated toward the left shoulder and the neck anteriorly flexed so that her chin approximated to the left clavicle (Fig. 1a). She could move her head voluntarily to a more erect position (Fig. 1b), but this effort was quickly overcome by two or three jerks as the head returned to its abnormal position. At rest, when seated in a chair or in bed, her head was more erect, but on first rising or on first sitting down the head deviation became maximal. The left sternomastoid and trapezius muscles seemed to be mildly hypertrophied. Her head could not be placed by the examiner in the normal position. A subsequent attempt was made under general anaesthesia to move her head to a normal position. This was without success because of fixed shortening of the neck muscles apparently secondary to her dystonia.

Her mental state was judged to be within normal limits. There were no involuntary facial movements. Her speech was normal, as was the remainder of the cranial nerve examination, with the exception of the VIIIth nerve (see below). Her gait appeared normal, though it was felt that her coordination for fine hand movements was symmetrically poor. There was no abnormality of power or tone in any of her extremities. The tendon and abdominal reflexes were symmetrical and normal. The

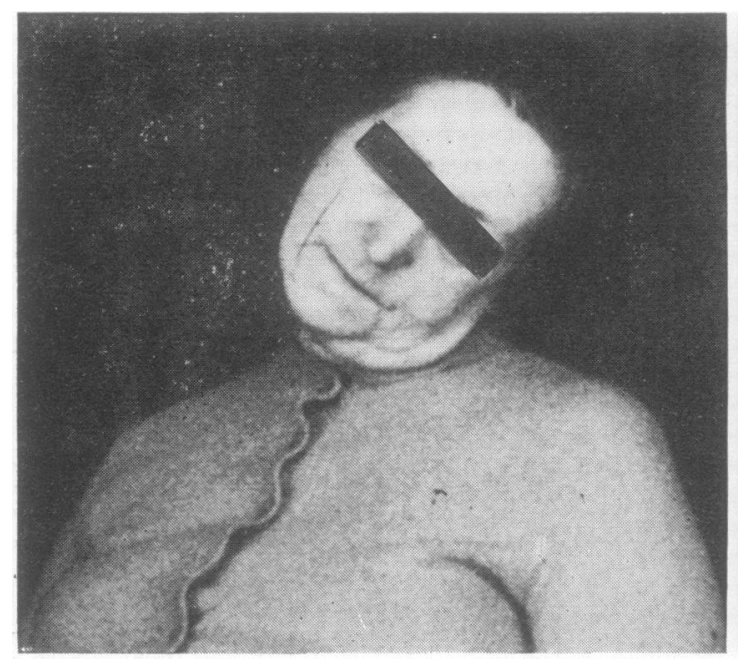

(a) plantar responses were flexor, and the sensory examina- $\bar{Z}$ tion was normal. Her blood pressure was $140 / 90 \mathrm{~mm} \mathrm{Hg}$ 을 There were marked bilateral varicosities of the superficia $\overline{6}$ leg veins. The remainder of the general physical examina tion was within normal limits.

Psychiatric evaluation (Dr. R. T. C. Pratt) revealed not evidence of past psychiatric disability apart from the episode of hysterical aphonia after a bombing raid in the war, and in particular there was no apparent psychological cause for the onset or perpetuation of her current. disability.

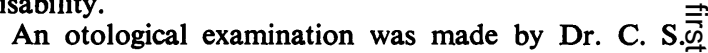
Hallpike. Nothing abnormal was detected in routineo examination of the ears, nose and throat. Neuro-oto-듬 logical testing showed no significant abnormality. Anç audiogram revealed normal hearing on the right side, and a moderate degree of high tone deafness of perceptive type on the left side. Vestibular function was withines normal limits, except for a slight reduction of the left $\overrightarrow{-}$ caloric responses. The optokinetic responses were present $t_{-}^{\circ}$ and equal to the left and right, up and down.

Shortly before her admission she had been evaluated as $\omega$ an in-patient at the Royal National Orthopaedic Hospital: A full radiological examination of the neck was carried out, including tomography of the cervical spine andiw radiographs of the neck in various positions under ${ }^{\omega}$ anaesthesia. Multiple degeneration of $C 5$ and 6 and $C 6$ and 7 intervertebral discs and cervical scoliosis, cons $8 x$ to the right, were demonstrated on the radiographs. bony cause for her torticollis was found.

TREATMENT AND SUBSEQUENT COURSE She had previousły been treated with a six-month course of neck traction without beneficial effect. An attempt at deconditioniag $\stackrel{\text { ? }}{?}$

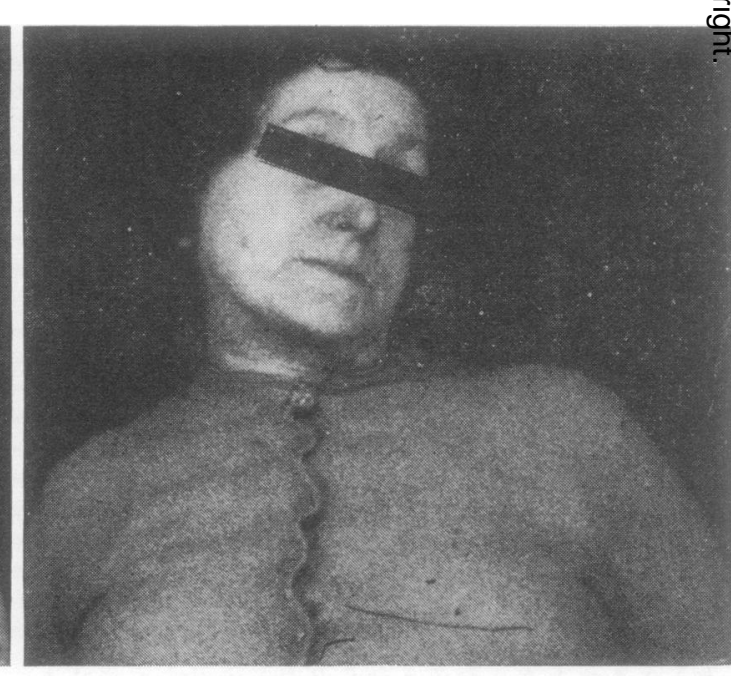

(b)

FIG. 1. Photographs taken in November 1959, two years after first symptoms. (a) shows left lateral flexion with slight N $^{\circ}$ anteroflexion of neck. (b) shows the extent to which the patient could move her head toward a normal position before her effort was overcome by spasmodic movements which would cause it to return to the position in (a). Some fixed shortening $\bigcirc$ of neck muscles had taken place by the time these photographs were made. 
therapy was made. She was fitted with a special collar through which a painful electric shock was delivered below the left mastoid process whenever her head went over into its abnormal position, but this was without lasting effect. There was no objective evidence of improvement on drug therapy (benzhexol, phenelzine, iproniazid, and meprobamate). Her condition did not change materially over the succeeding four years, and she was able to manage her solitary life without difficulty in spite of her disability, although she did not return to work.

FINAL HOSPITALIZATION In February 1962 she developed what appeared to be a viral gastritis. Neurological examination on 19 February 1962 (Dr. E. M. R. Critchley) showed that she had a very marked torticollis with her neck flexed anteriorly and laterally to the left. At rest there were no involuntary movements, but on trying to hold her head up she developed coarse, slow spasmodic involuntary movements tending to draw her head back into its abnormal position. Tone in the left sternomastoid seemed to be increased, while that in the right appeared normal. The left sternomastoid was examined with electromyography by Dr. H. R. A. Townsend. This was said to show a normal pattern.

While she was in the hospital a thrombophlebitis appeared, and subsequently, signs of bronchopneumonia. In spite of antibiotic therapy she died on 18 March 1962.

Necropsy The necropsy was performed 12 hours after death by Dr. R. C. Barnard.

The cervical spine showed a well-marked scoliosis, and the vertebrae were osteoporotic. The discs were soft and degenerated. There was no local lesion in the spine and the cord showed no evidence of pressure. The sternomastoid and trapezius muscles were said to appear normal, as were the cranium, dura mater, dural sinuses, and the cerebral vessels.

The right common iliac and femoral veins were distended with masses of thrombus, and both branches of the pulmonary artery contained preformed thrombi. There was widespread bronchopneumonia around areas of infarction in both lungs. The spleen was engorged and there were septic infarctions of both kidneys.

- Central nervous system The gross appearances of the brain and spinal cord were normal. Coronal slices of the brain revealed no abnormality to naked eye examination. Blocks from the frontal cortex, multiple levels of thalamus and basal ganglia, the vermis and cerebellar hemispheres, and the midbrain, upper, middle and lower pons, upper and lower medulla, cervical, thoracic, and lumbar cord were embedded in celloidin and sectioned frontally at

$+12 \mu$. These were stained with thionin, Gros-Bielschowsky, phosphotungstic acid-haematoxylin, Loyez-neutral red, haematoxylin - van Gieson and Luxol fast blue-cresyl violet stains. A separate series of thick sections at $24 \mu$ was stained with thionin. In addition, some blocks at selected levels were taken for staining with the Marchi method.

-Microscopic examination Figs. 2 and 3. The right and left frontal cortex showed slight thickening and mono- nuclear infiltration of the meninges. The cortical lamination was normal, without apparent neuronal loss or gliosis.

The caudate nucleus, putamen, globus pallidus, and red nucleus on both sides contained normal large and small neurones in normal proportions. The right and left substantiae nigrae showed normal neurones with what seemed normal amounts of pigment. The corpora Luysii and zonae incertae showed no abnormalities.

With the exception of the rostral tips of the interstitial nuclei of Cajal, which were taken for Marchi staining, the upper mesencephalon was sectioned at $10 \mu$. Serial sections at $240 \mu$ intervals stained with Luxol fast bluecresyl violet showed no abnormalities, nor did sections through the superior, lateral, medial, or spinal vestibular nuclei on either side. The cerebellar hemispheres, vermis, and cerebellar peduncles, and sections through the cervical thoracic, and lumbar spinal cord appeared normal.

Blood vessels were normal throughout. No cavitation was observed anywhere.

Serial sections of both temporal bones were examined with Dr. C. S. Hallpike. Apart from a very slight bulging of Reissner's membrane in the posterior basal coil on the left side, not felt to be significant in relation to the patient's torticollis, no abnormalities were found.

A second case of spasmodic torticollis, studied in detail clinically by Dr. Purdon Martin, was examined at necropsy in 1936 by Dr. J. G. Greenfield who found no abnormality in the brain or spinal cord. At the present time, the only sections available from this case (H.H.) are sections of the upper pons at the level of the superior cerebellar peduncles. No abnormalities were apparent on haematoxylin-van Gieson and Nissl stains.

\section{DISCUSSION}

Some neurologists have held the view that spasmodic torticollis is a hysterica! conversion reaction, a viewpoint recently summarized by Koupernik and Féline (1968). Indirect evidence for an organic basis for spasmodic torticollis comes from certain patients with encephalitis lethargica (Lhermitte and Lévy, 1929; Hassin, Schaub, and Voris, 1931) who at some stage present spasmodic jerking movements of the head. In addition, the rarity with which the disorder is successfully treated by psychiatric methods and the fact that spasmodic torticollis can be produced by focal lesions in the brains of experimental animals inclines me to the view that it must be caused in many human cases by a focal pathological change in the central nervous system and that, like other dyskinesias, it may be exacerbated by emotional factors.

The present study was stimulated by the experimental finding (Tarlov, 1969) that lesions involving the vestibular nuclei have markedly different postural effects in different primate species. Although vestibular nuclear lesions produce marked abnormal tonic postures of the head and neck in macaques, 


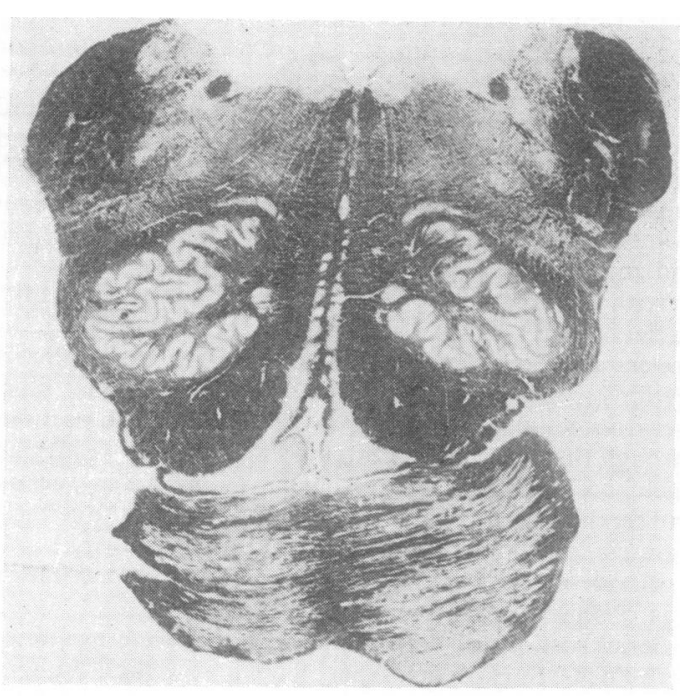

FIG. $2 \mathrm{a}$

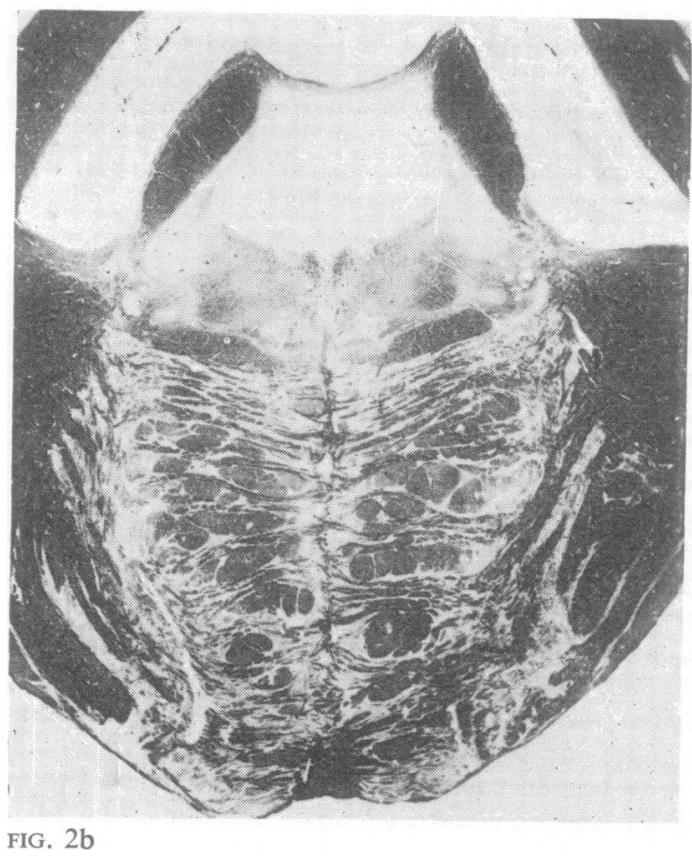

FIG. 2. (a) Section through medulla at level of descending (spinal) vestibular nucleus and inferior olives. (b) Level of upper pons, superior cerebellar peduncles and superior vestibular nuclei. (c) Upper mesencephalon and caudal thalamus, at level of posterior commissure and interstitial nuclei of Cajal (arrows). No abnormalities seen anywhere. Loyez stains, $\times 2 \cdot 5$.

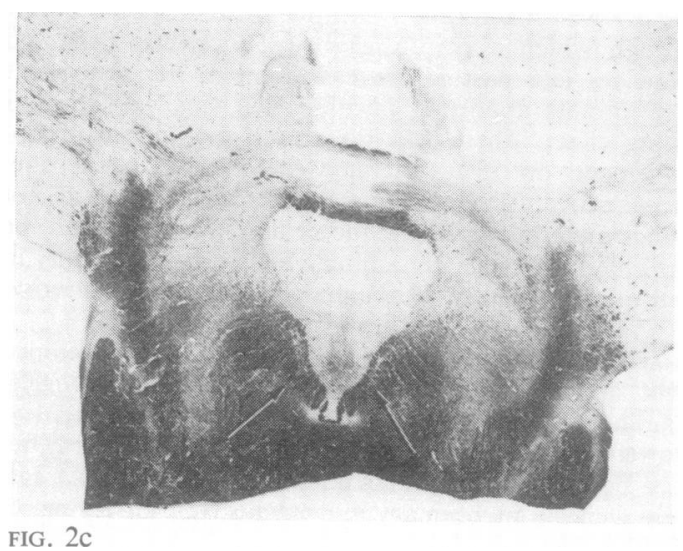

very much slighter abnormalities result from such lesions in the baboon and chimpanzee. This finding was of interest because experimental studies have revealed that focal lesions in the central nervous system in lower animals produce an involuntary spasmodic hyperkinesis of the neck which closely ${ }^{-}$ resembles spasmodic torticollis in man. Foltz, Knopp of and Ward (1959) found that a unilateral lesion of the medial mesencephalic reticular formation, caudi and dorsal to the red nucleus at the level of the decussation of the brachium conjunctivum, produces spasmodic torticollis in the monkey, and Mizawe (1963) reported identical findings in the cat. Althoug the lesion responsible for spasmodic torticollis if $\overrightarrow{0}$ man has never convincingly been demonstrated, 0 Foltz et al., and Mizawa infer that their experimental spasmodic torticollis may be relevant in explaining the pathogenesis of the condition in man.

Carpenter (1956) showed that lesions confined to the red nucleus in the monkey, 'provoke rotation and tilt the head to the side opposite the lesion.' From Carpenter's description the abnormal head posture was a tonic rather than a spasmodic head deviation. Denny-Brown (1962) reported that a lesion between the red nucleus and the interstitial nucleus of Cajal in the monkey caused a tonic neck torsion. The lesions of Carpenter and Denny-Brown which produced tonic torticollis in the monkey seem to be anatomically close to the lesions described by Foltz and his colleagues which produced a spasmodic torticollis. It is well known that in some patients with spasmodic torticollis, including the present patient, a tonic element may be present in addition to the spasmodic component.

Interest in the possible role of the interstitial nuclei of Cajal in torsion dystonia has been stimulated by the remarks of Denny-Brown $(1965,1967)$. For this reason a careful examination through 


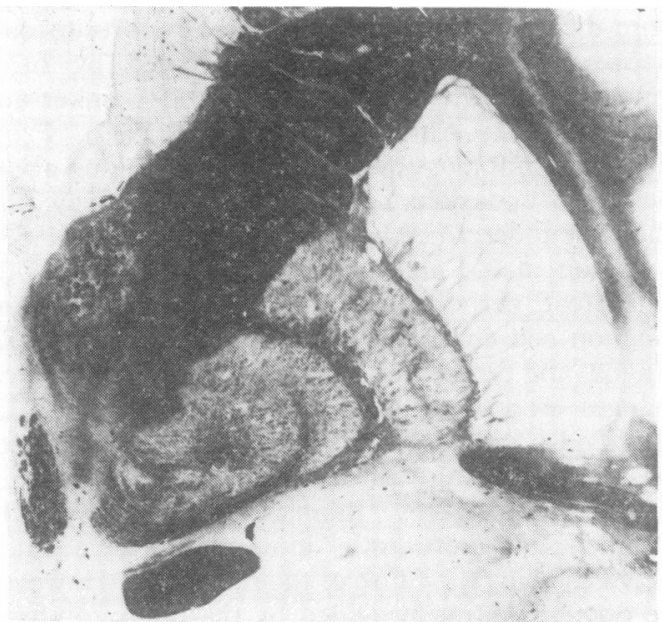

FIG. 3a

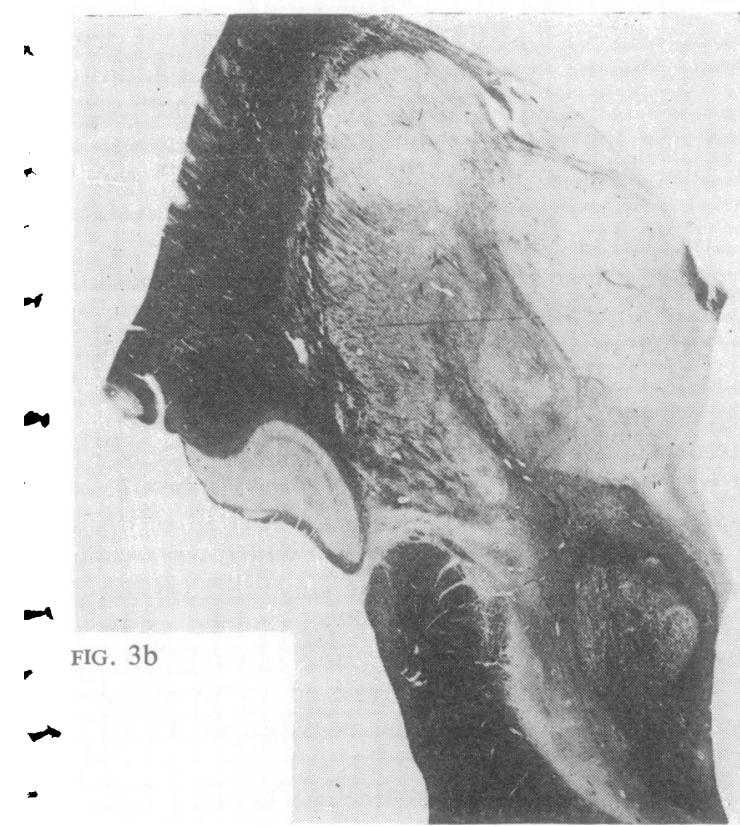

FIG. 3. (a) Right putamen, inner and outer segments of - globus pallidus. (b) Left red nucleus, tegmental fields and caudal thalamus. (c) Normal large and small cells, outer Tegment of left globus pallidus. (d) Normal cells, spinal vestibular nucleus. (e) Normal cells, interstitial nuclei of

- Cajal. (f) Normal cell, superior vestibular nucleus. (g) Normal cells, right substantia nigra. (a) and (b) Loyez ains, $\times 2 \cdot 5$. (c), (d), (e) and (f), Luxol fast blue-cresyl violet stains, $\times 525$. No differences were seen on the two - sides.

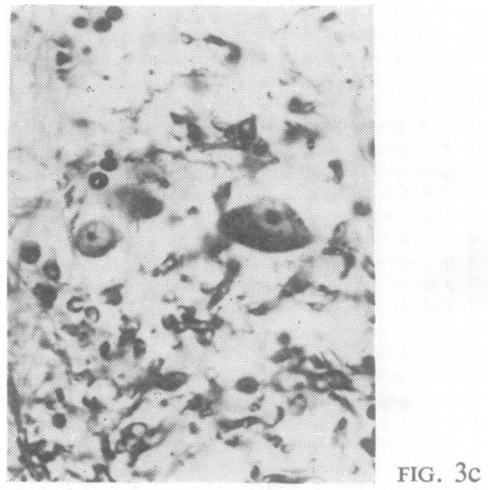

FIG. $3 d$
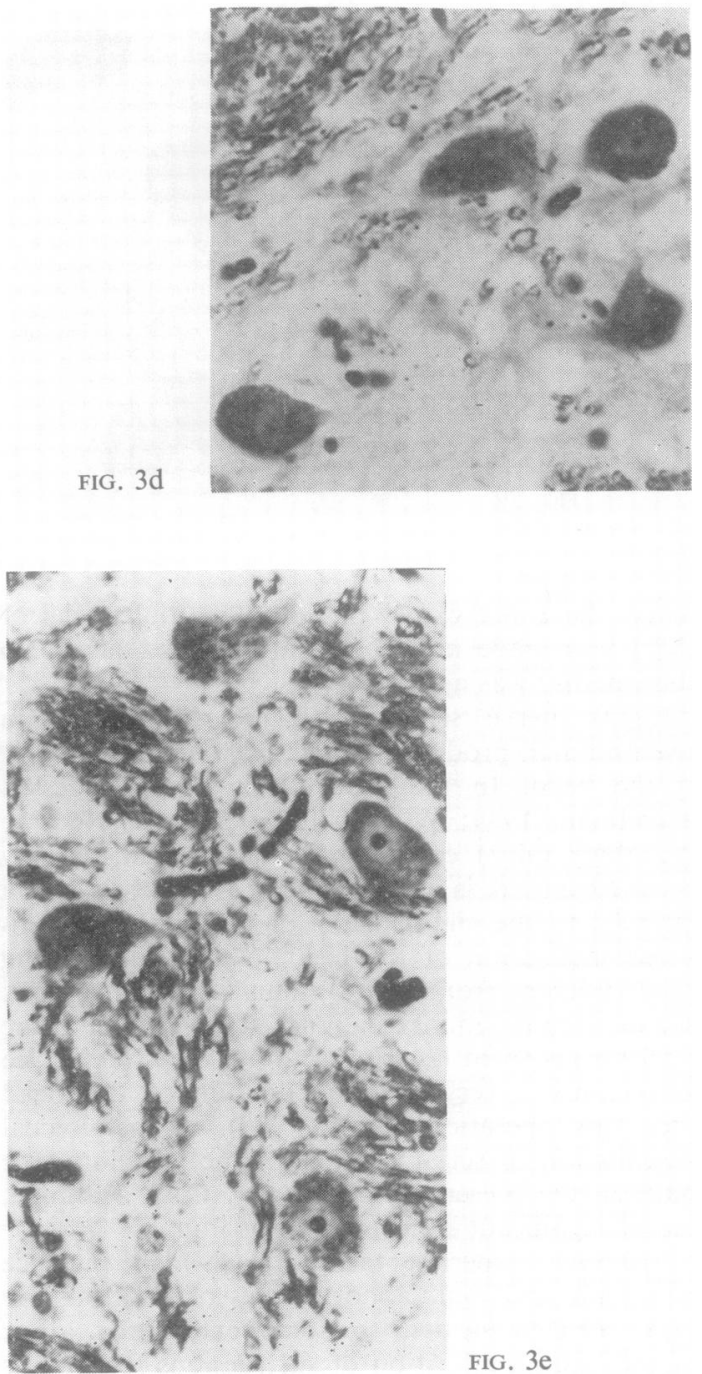

FIG. 3e 

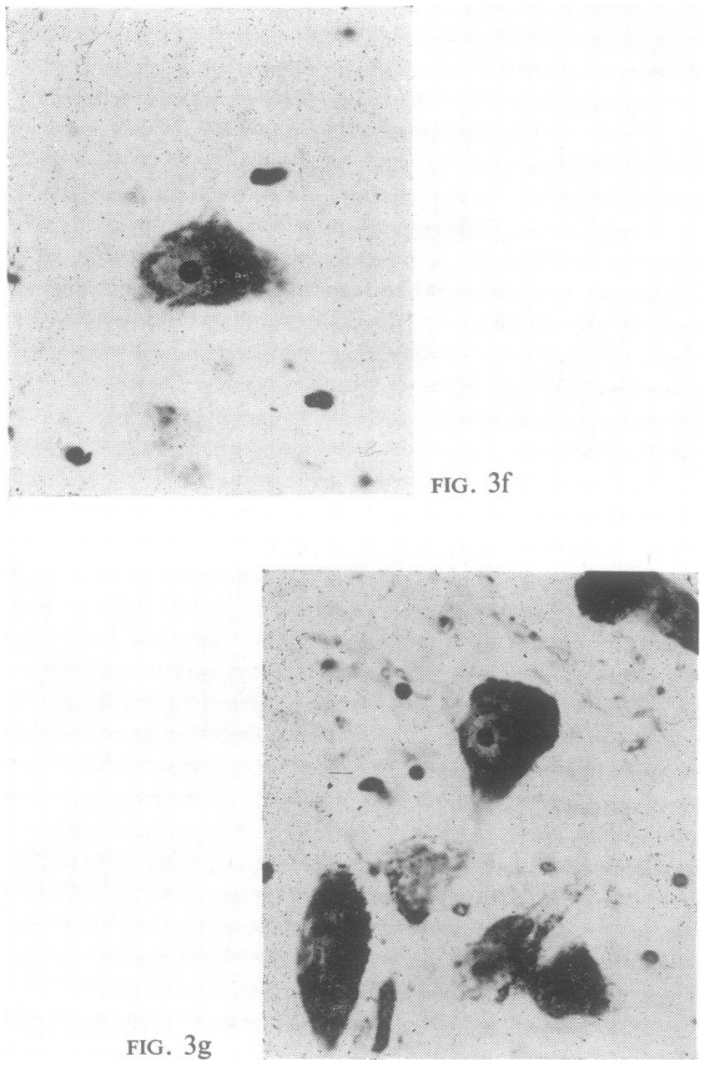

nearly the entire extent of the interstitial nuclei of Cajal was made in the patient reported here. No abnormality was apparent.

Eighth nerve section and labyrinthectomy in lower animals produce marked ipsilateral inclination of the head. In the past it has been suggested (Hyndman, 1939; Wilson, 1955) that labyrinthine pathology might cause torticollis in man. To my knowledge there is no confirmed case where a lesion confined to the eighth nerve or labyrinth has produced inclination of the head in man, man being quite different from lower animals in this respect. Although in the monkey a marked inclination of the head results from labyrinthectomy, the chimpanzee shows only a very slight inclination of the head after this operation (Dow, 1938). A histological examination of serial sections of the labyrinth was made in the present case with Dr. C. S. Hallpike, and no significant abnormality was found.

Although experimental lesions which produce spasmodic and tonic abnormalities of neck posture have been delineated to some extent for lower animals, the localization of such lesions for man is more difficult. There are only three reports to date of spasmodic torticollis uncomplicated by other abnormal movements (Foerster, 1933; Grinker andes Walker, 1933; Alpers and Drayer, 1937). From these it is not possible to draw conclusions abouto the lesion or lesions responsible for the torticollis. The patient described by Grinker and Walker (1933), a woman of 25 , had evidence of encephalitis with widespread perivascular round-cell infiltrations and? ganglion cell changes throughout the cortex, basa ganglia, and cerebellum; apparently the pathologica! changes were not asymmetrical. Foerster (1933) described a man of 23 afflicted with bilateral neck spasms producing retrocollis who died after acervical laminectomy. Bilateral cavitations of the putamen and substantia innominata were inter preted as being the cause of the retrocollis. However $\overrightarrow{0}$ the documentation provided by the photographs of the histological preparations is not entirely con-w vincing in view of the fact that similar changes have. frequently been seen in the brains of patients without torticollis. Alpers and Drayer (1937) described ot patient who died at the age of 90 . This case is com plicated by the fact that the patient had, in addition to spasmodic torticollis, bilateral choreoathetosis sy involving the upper extremities. There was loss कof ganglion cells in the caudate, putamen and globms. pallidus but evidently no difference on the two sides. A correlation between the various components ret disordered posture and alterations of the individea nuclei within the basal ganglia has recently been gat forth by Purdon Martin (1967), and therefore pathological changes in the basal ganglia in the case of Alpers and Drayer (1937) would have been of interest. However the bilateral changes described in a man of such advanced years can hardly be treatec as significant. There are also a number of recordeff cases examined at necropsy in which spasmodiळ torticollis was a part of a more generalized dystonia (Cassirer, 1922; Wimmer, 1929; Bouche and vars Bogaert, 1935; Gordin, 1939, and others). Becauseof the presence of a generalized dystonia, these reports do not establish the presence of a specific lesion responsible for torticollis.

No histological abnormality to account for the torticollis was found in this case. This fact howeve does not necessarily support the view that the disis order is a conversion reaction. Histological methods at best have certain limitations. For example, anything less than a marked loss of cells in any ganglion might be recognized only if we had very precise knowledge of the cell population numbers which could be accepted as normal-and, even then, onlso by counting of cells. Such data are not available. Th obtain them would be a formidable task, with many possible sources of error (see Treff, 1964). It is 
hoped that further well-studied cases will be collected and examined. Generalizations may then be possible, and these may be of help in planning rational therapy for this disorder.

It is a pleasure to thank Dr. Marion C. Smith for her suggestions and for making possible the study of the specimens in her laboratory. Thanks are also due to Dr. R. T. C. Pratt for access to his case notes, Dr. C. S. Hallpike for examining the temporal bones, Dr. R. C. Barnard for the general necropsy findings, and Dr. George du Boulay for reviewing the radiographs. The histological sections were prepared by Miss Patricia Deacon and the photomicrographs by Mr. Leslie Frampton.

\section{REFERENCES}

Alpers, B. J., and Drayer, C. S. (1937). The organic background of some cases of spasmodic torticollis: report of a case with autopsy. Amer. J. med. Sci., 193, 378-384.

Bouché, G., and van Bogaert, L. (1935). Étude anatomoclinique d'un état đe rigidité unilatérale progressive avec choréo-athétose et paroxysmes de torsion autour de l'axe longitudinal. Rev. neurol., 64, 886-901.

Carpenter, M. B. (1956). A study of the red nucleus in the rhesus monkey. Anatomical degenerations and physiological effects resulting from localized lesions of the red nucleus. J. comp. Neurol., 105, 195-249.

Carrea, R. M. E., and Mettler, F. A. (1955). Function of the primate brachium conjunctivum and related structures. J. comp. Neurol., 102, 151-322.

Cassirer, R. (1922). Halsmuskelkrampf und Torsionsspasmus. Klin. Wschr., 1, 53-57.

Denny-Brown, D. (1962). The midbrain and motor integration. Proc. roy. Soc. Med., 55, 527-538.

Denny-Brown, D. (1965). The nature of dystonia. Bull. N.Y. Acad. Med., 41, 858-869.

Denny-Brown, D. (1967). The fundamental organization of motor behavior. In Neurophysiological Basis of Normal and Abnormal Motor Activities, pp. 415-444. Proceedings of the 3rd symposium of the Parkinson's Disease Information and Research Center of Columbia
University. Edited by M. D. Yahr and D. P. Purpura. Hewlett, New York, Raven Press.

Dow, R. S. (1938). The effects of unilateral and bilateral labyrinthectomy in monkey, baboon and chimpanzee. Amer. J. Physiol., 121, 392-399.

Foerster, O. (1933). Mobile spasm of the neck muscles and its pathological basis. J. comp. Neurol., 58, 725-735.

Foltz, E. L., Knopp, L. M., and Ward, A. A. (1959). Experimental spasmodic torticollis. J. Neurosurg., 16, 55-72.

Gordin, R. (1939). A case of unilateral torsion-dystonia. A clinico-histological study. J. nerv. ment. Dis., 90, 344-357.

Grinker, R. R., and Walker, A. E. (1933). The pathology of spasmodic torticollis with a note on respiratory failure from anaesthesia in chronic encephalitis. J. nerv. ment. Dis., 78, 630-637.

Hassin, G. B., Schaub, C. F., and Voris, H. C. (1931). Spasmodic torticollis. Arch. Neurol. Psychiat. (Chic.), 26, 1043-1052.

Hyndman, O. R. (1939). Torticollis spastica. Suggested etiologic relation to the vestibular apparatus; report of a case. Arch. Otolaryng., 29, 927-938.

Kemberling, S. R., Baird, H. W. and Spiegel, E. A. (1952). Experimental torticollis of rhombencephalic origin. $J$. Neuropath. exp. Neurol., 11, 184-191.

Koupernik, C., and Féline, A. (1968). Torticollis spasmodique. Concours mèd., 90, 3573-3581.

Lhermitte, J., and Lévy, G. (1929). Remarques cliniques sur le torticolis spasmodique. Le torticolis cérébral. Rev. neurol., 1, 1025-1033.

Martin, J. P. (1967). The Basal Ganglia and Posture, pp. 100-105. Pitman: London.

Mizawa, I. (1963). Experimental spasmodic torticollis in cat. Arch. jap. Chir., 32, 597-624.

Tarlov, E. (1969). The postural effect of lesions of the vestibular nuclei: a note on species differences among primates. J. Neurosurg., 31, 187-195.

Treff, W. M. (1964). Numerische und Volumenzelldichte im Caudatum Mediale: mit Besonderer Berücksichtigung des quantitaven Auswertungsfehlers bei Zellzahlung. Progress in Brain Research, 6, 139-146.

Wilson, S. A. K. (1955). Neurology, vol. 3, pp. 1953-1963. Edited by A. N. Bruce. Butterworth: London.

Wimmer, A. (1929). Le spasme de torsion. Rev. neurol., 1, 904-915. 